University of Wollongong

Research Online

Australian Institute for Innovative Materials -

Papers

Australian Institute for Innovative Materials

$1-1-2015$

Growth of MoS2@C nanobowls as a lithium-ion battery anode material

Chunyu Cui

Hunan University

Xiu Li

Hunan University

Zhe Hu

University of Wollongong, zh865@uowmail.edu.au

Jiantie Xu

University of Wollongong, jxx125@case.edu

Hua-Kun Liu

University of Wollongong, hua@uow.edu.au

See next page for additional authors

Follow this and additional works at: https://ro.uow.edu.au/aiimpapers

Part of the Engineering Commons, and the Physical Sciences and Mathematics Commons

Research Online is the open access institutional repository for the University of Wollongong. For further information contact the UOW Library: research-pubs@uow.edu.au 


\title{
Growth of MoS2@C nanobowls as a lithium-ion battery anode material
}

\begin{abstract}
Layered MoS2 has attracted much attention as a promising anode material for lithium ion batteries. The intrinsically poor electrical/ionic conductivity, volume expansion and pulverization, stress accumulation and unstable solid-electrolyte interface formation within MoS2 electrodes during the lithiation-delithiation process significantly result in their fast capacity fading, poor rate capability and cycle life. To address these critical issues, a novel nanobowl structure for MoS2 with a carbon coating (MoS2@C-400, 500, 600) is successfully fabricated by a facile solvothermal method, followed by a post-annealing process. The fabricated MoS2@C-600 and MoS2@C-500 exhibited high reversible capacities of 1164.4 and 1076.4 mA h g-1 at $0.2 C$, and maintained high capacity retention of $72.1 \%$ and $78.4 \%$ over 150 cycles, respectively. Such remarkable lithium storage properties are attributed to the unique nanobowl structure, which provides a large accessible surface area and high pore volume, and flexible carbon film coating, allowing for easy diffusion of electrolyte, alleviation of volume expansion, formation of stable solid electrolyte interfaces and fast diffusion of lithium ions.
\end{abstract}

\section{Keywords}

mos2, c, nanobowls, growth, lithium, material, ion, battery, anode

Disciplines

Engineering | Physical Sciences and Mathematics

\section{Publication Details}

Cui, C., Li, X., Hu, Z., Xu, J., Liu, H. \& Ma, J. (2015). Growth of MoS2@C nanobowls as a lithium-ion battery anode material. RSC Advances: an international journal to further the chemical sciences, 5 (112), 92506-92514.

\section{Authors}

Chunyu Cui, Xiu Li, Zhe Hu, Jiantie Xu, Hua-Kun Liu, and Jianmin Ma 


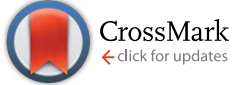

Cite this: RSC Adv., 2015, 5, 92506
Received 4th September 2015 Accepted 21st October 2015

DOI: 10.1039/c5ra17992k

www.rsc.org/advances

\section{Growth of $\mathrm{MoS}_{2} \mathrm{aC}$ nanobowls as a lithium-ion battery anode material $\uparrow$}

\begin{abstract}
Chunyu Cui, ${ }^{\mathrm{a}}$ Xiu Li ${ }^{a}{ }^{\mathrm{a}}$ Zhe Hu, ${ }^{\mathrm{b}}$ Jiantie $\mathrm{Xu}{ }^{\text {*b }}$ Huakun Liu ${ }^{\mathrm{b}}$ and Jianmin Ma*ab
Layered $\mathrm{MoS}_{2}$ has attracted much attention as a promising anode material for lithium ion batteries. The intrinsically poor electrical/ionic conductivity, volume expansion and pulverization, stress accumulation and unstable solid-electrolyte interface formation within $\mathrm{MoS}_{2}$ electrodes during the lithiationdelithiation process significantly result in their fast capacity fading, poor rate capability and cycle life. To address these critical issues, a novel nanobowl structure for $\mathrm{MoS}_{2}$ with a carbon coating $\left(\mathrm{MoS}_{2} @ \mathrm{CC}-400\right.$, 500,600 ) is successfully fabricated by a facile solvothermal method, followed by a post-annealing process. The fabricated $\mathrm{MoS}_{2} \mathrm{aC}-600$ and $\mathrm{MoS}_{2} \mathrm{aC}-500$ exhibited high reversible capacities of 1164.4 and $1076.4 \mathrm{~mA} \mathrm{~h} \mathrm{~g}^{-1}$ at $0.2 \mathrm{C}$, and maintained high capacity retention of $72.1 \%$ and $78.4 \%$ over 150 cycles, respectively. Such remarkable lithium storage properties are attributed to the unique nanobowl structure, which provides a large accessible surface area and high pore volume, and flexible carbon film coating, allowing for easy diffusion of electrolyte, alleviation of volume expansion, formation of stable solid electrolyte interfaces and fast diffusion of lithium ions.
\end{abstract}

\section{Introduction}

Lithium-ion batteries (LIBs) have attracted increasing research interest and become one of the main power supplies for smart electronic devices and electric vehicles (EVs) and hybrid EVs (HEVs) due to their advantages of high power/energy density, long cycling life, and environmental friendliness. ${ }^{1}$ In order to acquire even higher energy density of LIBs, the development of high-energy electrode materials is the key to success. ${ }^{2}$ In the commercial market, graphite as an anode material has been commonly used in LIBs for the past two decades owing to its rich natural resources, low cost, and good cycling stability. Its low theoretical capacity $\left(\sim 372 \mathrm{~mA} \mathrm{~h}^{-1}\right)$, poor rate performance and plating (deposition) of metallic $\mathrm{Li}$ at $\sim 0.05 \mathrm{~V}\left(v s . \mathrm{Li}^{+} / \mathrm{Li}\right)$, however, limit its further application in high-energy EVs and HEVs. Graphene, a crystalline allotrope of carbon with 2dimensional (2D) properties, has been widely investigated for energy conversion/storage applications due to its unique physical and chemical properties. ${ }^{3}$ In terms of its application as anode for LIBs, graphene exhibited much higher capacity and rate capability than graphite because of its larger surface area, higher electronic conductivity, and remarkable thermal and mechanical stability. ${ }^{4}$

${ }^{a}$ School of Physics and Electronics, Hunan University, Changsha, China, 410082. E-mail: nanoelechem@hnu.edu.cn; Jianm@uow.edu.au

${ }^{b}$ Institute for Superconducting and Electronic Materials, University of Wollongong, Wollongong, Australia,2500.E-mail: jx307@uowmail.edu.au

$\dagger$ Electronic supplementary information (ESI) available. See DOI: $10.1039 / \mathrm{c} 5 \mathrm{ra} 17992 \mathrm{k}$
Analogue to graphene, two-dimensional transition-metal layered transition-metal dichalcogenides have also been widely investigated as anode materials in reversible storage of $\mathrm{Li}$ to replace the graphite, as well as graphene. ${ }^{5} \mathrm{MoS}_{2}$, one of the $\mathrm{MX}_{2}$-type $(\mathrm{M}=\mathrm{Ti}, \mathrm{Nb}, \mathrm{Mo}, \mathrm{Ta} ; \mathrm{X}=\mathrm{S}$, Se, Te) compounds, possesses a layered crystal structure that is stacked layer-bylayer in the order of 'S-Mo-S', in which the S-S layers are supported by van der Waals forces and Mo atoms are sandwiched in the center between S-S layers. ${ }^{6}$ These structural features provide strong molecular bonds within a single layer but weak interlayer bonds, and thus facilitate the insertion/extraction of $\mathrm{Li}^{+}$ions, leading to a high theoretical capacity of $\sim 670 \mathrm{~mA} \mathrm{~h} \mathrm{~g}^{-1}$ based on $4 \mathrm{Li}^{+}$ions reacted with every $\mathrm{MoS}_{2}$ molecule. Owing to its high theoretical capacity, as well as its rich natural resources, $\mathrm{MoS}_{2}$ has been extensively demonstrated to be an ideal anode material for LIBs. ${ }^{7}$

To date, intrinsically poor electrical/ionic conductivity, volume expansion and pulverization, stress accumulation and unstable solid-electrolyte interface formation within $\mathrm{MoS}_{2}$ electrode during the lithiation-delithiation process significantly result fast capacity fading, poor rate capability and cycle life. To solve these critical issues, many efforts have been made, including morphology control, ${ }^{8-13}$ hybridizing $\mathrm{MoS}_{2}$ nanostructures with more conductive materials (e.g., porous carbon, carbon nanotubes, and graphene),${ }^{8-18}$ and enlarging the lattice in the $c$-direction between S-S layers. ${ }^{19}$ Among these efforts, nanostructure engineering and hybridization with more conductive materials of $\mathrm{MoS}_{2}$ have been proven to be an effective method. Typically, hollow structures for electrode materials have been widely demonstrated to be beneficial to enhance electrical/ionic 
conductivity and buffer volume expansion. The hollow structures not only provide free spaces to alleviate the structural strain during the lithium insertion/extraction process, but also facilitate the fast diffusion of lithium ions in large accessible areas and by short diffusion paths, leading to improved rate capability and cycling stability. Despite the structural advantages of hierarchical hollow $\mathrm{MoS}_{2},{ }^{12,17}$ as well as $\mathrm{MoS}_{2}$ microspheres, ${ }^{8} \mathrm{MoS}_{2} /$ polyaniline nanowires, ${ }^{10} \mathrm{MoS}_{2} /$ carbon nanoflake, ${ }^{\mathbf{1 3}, 18}$ honeycomb-like $\mathrm{MoS}_{2},{ }^{11}$ and $\mathrm{MoS}_{2}$ /graphene nanoflowers, the further enhancement of the capacity, rate capability and cycling stability of $\mathrm{MoS}_{2}$ is still highly desirable.

Here, for the first time, we synthesized novel nanobowl structures for $\mathrm{MoS}_{2} @ \mathrm{C}$ by a facial solvothermal method, followed by an annealing process. Apart from the structural advantages of hollow spheres or other closed hollow structures, the bowl-like nanostructure of $\mathrm{MoS}_{2} @ \mathrm{C}$ with open interior and exterior surfaces provides extra excellent/enhanced characteristics to further enhance the electrochemical performance. For example, it includes: (i) higher accessible specific surface area and surface to volume ratio than the hollow structure, offering more accessible areas from the interfacial contact areas to facilitate the quick penetration of electrolyte and more lithium ion storage; (ii) amorphous carbon films coated on not only the exterior, but also the interior surfaces of $\mathrm{MoS}_{2}$ to protect electrodes from pulverization and enhance the conductivity of $\mathrm{MoS}_{2}$, enabling fast electron transportation across the interface of the $\mathrm{MoS}_{2}$ and the carbon sheets; and (iii) a 'sandwich-like' amorphous carbon coating to enhance the mechanical flexibility and maintain the structural integrity of $\mathrm{MoS}_{2}$, as well as alleviating its volume changes. Therefore, by integrating these advantages of both nanostructure engineering and hybridization, we found that the $\mathrm{MoS}_{2}$ @C-600 exhibited the high initial capacity of $1558.3 \mathrm{~mA} \mathrm{~h} \mathrm{~g}^{-1}$ at $0.1 \mathrm{C}$ and $1164.4 \mathrm{~mA} \mathrm{~h}^{-1}$ at $0.2 \mathrm{C}$ while $\mathrm{MoS}_{2} @ \mathrm{C}-500$ maintained a high reversible capacity of 846 $\mathrm{mA} \mathrm{h} \mathrm{g}^{-1}$ at $0.2 \mathrm{C}$ over 150 cycles, corresponding to an initial capacity retention of $78.4 \%$. The capacity and cycle stability was considerably enhanced compared to $\mathrm{MoS}_{2}$-graphene (808 $\mathrm{mA} \mathrm{h} \mathrm{g}{ }^{-1}$ retained after 100 cycles, $\left.100 \mathrm{~mA} \mathrm{~g}^{-1}\right),{ }^{16}$ and $\mathrm{MoS}_{2}-\mathrm{C}$ $\left(698 \mathrm{~mA} \mathrm{~h} \mathrm{~g}^{-1}\right.$ retained after 60 cycles, $\left.100 \mathrm{~mA} \mathrm{~g}^{-1}\right){ }^{{ }^{14}}$

\section{Experimental section}

\subsection{Synthesis of $\mathrm{MoS}_{2}$}

Firstly, sodium molybdate and thioacetamide were dissolved in deionized water and $N$-methyl pyrrolidone (NMP) with continuous stirring for 30 minutes. Secondly, the obtained mixture was transferred into a $50 \mathrm{~mL}$ Teflon-lined stainless steel autoclave and maintained at $200{ }^{\circ} \mathrm{C}$ for $24 \mathrm{~h}$. Thirdly, the reaction system was naturally cooled down to room temperature. Finally, the obtained products were collected by centrifugation, washed with distilled water and ethanol, and dried at $60{ }^{\circ} \mathrm{C}$ under vacuum.

\subsection{Synthesis of $\mathrm{MoS}_{2} @ \mathrm{C}$}

Firstly, $0.1 \mathrm{~g}$ of the as-prepared $\mathrm{MoS}_{2}$ and $5 \mathrm{~mL}$ oleic acid were mixed, and the mixture was kept under stirring for $24 \mathrm{~h}$ in a $40^{\circ}$ thermostatic water bath. Secondly, the obtained mixture was collected by centrifugation and washed with ethanol, which was followed by an annealing process in Ar atmosphere at a heating rate of $3^{\circ} \mathrm{min}^{-1}$ at temperatures of $400^{\circ}, 500^{\circ}$, and $600^{\circ}$ for $2 \mathrm{~h}$, and finally, naturally cooling to room temperature.

\subsection{Materials characterizations}

The morphologies and structures of the as-prepared samples were characterized by scanning electron microscopy (SEM) on a Hitachi S-4800, with both transmission electron microscopy (TEM) and high-resolution TEM (HRTEM) on a JEOL2010. The phase of the as-prepared samples was identified by X-ray diffraction (XRD) using a Rigaku D max-2500. Raman spectra were collected on a Lab RAM HR 800 Raman spectrometer. X-ray photoelectron spectra (XPS) were acquired on an ESCALAB 250. The Brunauer-Emmett-Teller (BET) measurements were carried out using a Micromeritics ASAP 2020 system. Pore size distribution (PSD) curves were obtained from $\mathrm{N}_{2}$ adsorption data by the density functional theory (DFT) method (Micromeritics). Thermogravimetric analysis (TGA, Setaram018124) was performed at a heating rate of $10{ }^{\circ} \mathrm{C} \mathrm{min}^{-1}$ in air.

\subsection{Electrochemical measurements}

The electrodes were fabricated by blending the MoS2, MoS2@C400, MoS2@C-500, or MoS2@C-600 with acetylene black carbon and polyvinylidene difluoride (PVDF), in a weight ratio of $8: 1: 1$, respectively. $N$-Methyl-2-pyrrolidone (NMP) was used as the blending solvents for the mixture. The obtained slurry was coated on $\mathrm{Cu}$ foil, dried at 90C for $12 \mathrm{~h}$, and cut into electrodes. The obtained electrodes were dried again at 90C for $12 \mathrm{~h}$ in vacuum. CR 2032 coin-type cells were assembled using the asprepared electrode as the working electrode, Li foil as the counter electrode and reference electrode, porous polypropylene film as the separator, and $1 \mathrm{M}$ LiPF6 in a $1: 1: 1$ $(\mathrm{v} / \mathrm{v} / \mathrm{v})$ mixture of ethylene carbonate (EC), ethylene carbonate (EC), and diethyl carbonate (DEC) as the electrolyte. The performance of the cells was measured using an automatic battery tester system (Land ${ }^{\circledR}$, China) and galvano statically charged and discharged at various current densities in the voltage range of $0.02-3.0 \mathrm{~V}$, with $1 \mathrm{C}=500 \mathrm{~mA} \mathrm{~g}^{-1}$. Cyclic voltammograms (CV) and electrochemical impedance spectra (EIS) were collected using a $\mathrm{CHI}$ 760C (CH Instruments, USA) electrochemical workstation over a frequency range of $50 \mathrm{mHz}$ to $1 \mathrm{MHz}$. Owing to the low amount of carbon, only $\sim 5 \mathrm{wt} \%$, the capacity contribution from carbon was neglected. Moreover, the specific capacity and C-rates of MoS2@C were calculated based on the total mass of MoS2@C.

\section{Results and discussion}

The fabrication process of $\mathrm{MoS}_{2} @ \mathrm{C}$ nanobowls is simply illustrated in Fig. 1. The $\mathrm{MoS}_{2}$ nanobowls were initially synthesized by a solvothermal reaction using sodium molybdate (SM) and thioacetamide (TAA) in $N$-methyl pyrrolidone (NMP) $/ \mathrm{H}_{2} \mathrm{O}$ at $200{ }^{\circ} \mathrm{C}$ for $24 \mathrm{~h}$. To explore the influence of synthesis conditions on the morphology and structure of $\mathrm{MoS}_{2}$, a series of $\mathrm{MoS}_{2}$ 


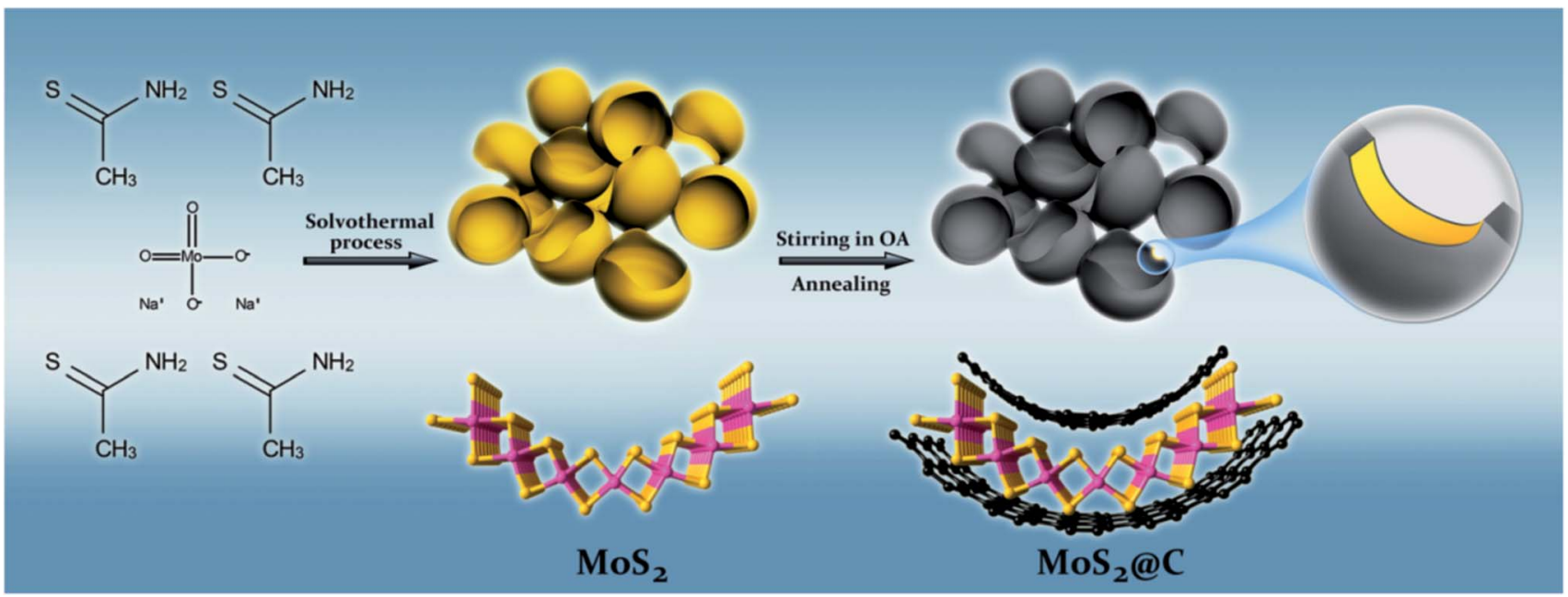

Fig. 1 Schematic illustration of the formation mechanism of the $\mathrm{MoS}_{2}$ aC nanobowls (OA: oleic acid).

prepared by using different volume ratios of solvents (NMP/ $\mathrm{H}_{2} \mathrm{O}, 0: 4,1: 3,2: 2,3: 1$ and $\left.4: 0\right)$ and mass ratios of solutes (SM/TAA, $1: 1,1: 1.5,1: 2,2: 2,4: 4)$ are compared in Experimental section (ESI, Table S1 $\dagger$ ). Based on the optimal synthesis condition, the formation mechanism of $\mathrm{MoS}_{2}$ nanobowls is proposed. Initially, the growth in the [001] or [002] direction of $\mathrm{MoS}_{2}$ is strongly hindered because of the blocking effect of $-\mathrm{OH}$ on the crystal planes (e.g., (001) or (002)), leading to the formation of $\mathrm{MoS}_{2}$ monolayers. ${ }^{20}$ In the following step, the adjacent $\mathrm{MoS}_{2}$ monolayers that bonded by van der Waals forces self-assemble to form nanoflakes, then the $\mathrm{MoS}_{2}$ nanoflakes stack and form the sheet structure that is thinner at the edge and thicker in the middle. ${ }^{21}$ Driven by ever-growing thermodynamic forces, the thinner edges of the $\mathrm{MoS}_{2}$ sheets become curled up to make the $2 \mathrm{D}$ architectures more stable, and the lamellar structures at the edge gradually grow upwards. Simultaneously, the thicker middle of the $\mathrm{MoS}_{2}$ sheets forms as the bottom of a sphere-shaped bowl. Since the surface energy of $\mathrm{MoS}_{2}$ reaches a fixed value with $\mathrm{MoS}_{2}$ ever growing, the unique nanobowl structure of the $\mathrm{MoS}_{2}$ remains stable. In order to further enhance the anode performance of $\mathrm{MoS}_{2}$, a series of the as-synthesized $\mathrm{MoS}_{2}$ nanobowls with carbon coating $\left(\mathrm{MoS}_{2} @ \mathrm{C}\right)$ are prepared by annealing mixtures of $\mathrm{MoS}_{2} /$ oleic acid (OA) at $400{ }^{\circ} \mathrm{C}, 500{ }^{\circ} \mathrm{C}$, and $600{ }^{\circ} \mathrm{C}$. During this annealing process, the $\mathrm{OA}$ is expected to be carbonized to a thin carbon film that uniformly coated inner and outer surfaces of the $\mathrm{MoS}_{2}$ nanobowls. More details of the synthesis procedure are presented in the Experimental section. The obtained $\mathrm{MoS}_{2} @ \mathrm{C}$ annealed at $400{ }^{\circ} \mathrm{C}, 500{ }^{\circ} \mathrm{C}$ and $600{ }^{\circ} \mathrm{C}$ were denoted as $\mathrm{MoS}_{2} @ \mathrm{C}-400$, $\mathrm{MoS}_{2} @ \mathrm{C}-500$, and $\mathrm{MoS}_{2} @ \mathrm{C}-600$, respectively.

The morphologies and structures of the as-prepared $\mathrm{MoS}_{2}$ and $\mathrm{MoS}_{2} @ \mathrm{C}$ samples are systematically investigated by scanning electron microscopy (SEM) and transmission electron microscopy (TEM). As can be seen, Fig. 2a-d displays that all $\mathrm{MoS}_{2}, \mathrm{MoS}_{2} @ \mathrm{C}-400, \mathrm{MoS}_{2} @ \mathrm{C}-500$ and $\mathrm{MoS}_{2} @ \mathrm{C}-600$ are composed of the nanobowls with a uniform size of $\sim 50 \mathrm{~nm}$ in diameter. As expected, there were no distinct morphology changes for $\mathrm{MoS}_{2}$ and $\mathrm{MoS}_{2} @ \mathrm{C}$, indicating the excellent structural stability of $\mathrm{MoS}_{2}$ nanobowls after annealing. The detailed structures and sizes of $\mathrm{MoS}_{2}$ and $\mathrm{MoS}_{2} @ \mathrm{C}$ nanobowls were also further confirmed by TEM (Fig. 2e-h) and highresolution TEM (HR-TEM) (Fig. 2i-l). As shown in Fig. 2i, $\mathrm{MoS}_{2}$ was composed of a ring-like structure with 3-7 lamellar layers. The ring-like structures have a lattice spacing of $0.68 \mathrm{~nm}$ between lamellar layers corresponding to a distance between (002) planes of $\mathrm{MoS}_{2}$. After pyrolysis of the carbon precursor, the lattice spacing of $\mathrm{MoS}_{2} @ \mathrm{C}$ was slightly decreased from 0.68 to $0.62 \mathrm{~nm}$. The decreased lattice spacing could be ascribed to recrystallization and removal of structural defects of $\operatorname{MoS}_{2} \cdot{ }^{8,13,15,16}$

Fig. 3a displays the XRD patterns of $\mathrm{MoS}_{2}, \mathrm{MoS}_{2} @ \mathrm{C}-400$, $\mathrm{MoS}_{2} @ \mathrm{C}-500$, and $\mathrm{MoS}_{2} @ \mathrm{C}-600$. As shown in Fig. 3a, $\mathrm{MoS}_{2}$ exhibits four distinct peaks at $9.0^{\circ}, 17.8^{\circ}, 32.5^{\circ}$, and $57.5^{\circ}$. Two broadened peaks in the high-angle regions $\left(32.5^{\circ}\right.$ and $\left.57.0^{\circ}\right)$ correspond to the (100) and (110) planes, respectively. The peak at $17.8^{\circ}$ is indexed to the reflection of (002) plane while the peak at $9.0^{\circ}$ is assigned to the (001) plane. ${ }^{14}$ After the annealing process, all the XRD peaks of $\mathrm{MoS}_{2} @ \mathrm{C}-400, \mathrm{MoS}_{2} @ \mathrm{C}-500$, and $\mathrm{MoS}_{2} @ \mathrm{C}-600$ are well indexed to hexagonal $\mathrm{MoS}_{2}$ (JCPDS card no. 73-1508), including a $14.9^{\circ}$ main peak, which can be assigned to the (002) plane. As can be seen, the presence of the peak at $14.9^{\circ}$ but disappearance of two peaks at $9^{\circ}$ and $17.8^{\circ}$ are due to the removal of structural defects and recrystallization of $\mathrm{MoS}_{2}$ after the annealing process, leading to the decrease in the layer-by-layer lattice spacing. ${ }^{17}$ These results are consistent with the HRTEM results (Fig. 2i-l). Raman spectroscopy (Fig. 3b) reveals the $\mathrm{MoS}_{2}$ structure with the appearance of two characteristic peaks at $379 \mathrm{~cm}^{-1}$ and $403 \mathrm{~cm}^{-1}$, corresponding to the $\mathrm{E}_{2 \mathrm{~g}}^{1}$ and $\mathrm{A}_{\mathrm{g}}^{1}$ modes, respectively. ${ }^{17}$ As expected, $\mathrm{MoS}_{2} @ \mathrm{C}$ composites all display typical $E_{2 g}^{1}$ and $A_{g}^{1}$ modes in the same region. In addition, the characteristic $\mathrm{D}$ band (a defect/disorder peak) at $1370 \mathrm{~cm}^{-1}$ and $\mathrm{G}$ band (a graphitic peak) at $1580 \mathrm{~cm}^{-1}$ further confirm the presence of carbon in the $\mathrm{MoS}_{2} @ \mathrm{C}$. The intensity ratio of $I_{\mathrm{D}} / I_{\mathrm{G}}$ decreased from $\mathrm{MoS}_{2} @ \mathrm{C}-400, \mathrm{MoS}_{2} @ \mathrm{C}-$ 500, to $\mathrm{MoS}_{2} @ \mathrm{C}-600$. It is mainly due to higher degree of carbonization of carbon nanosheets at higher annealing temperature. As expected, the high crystallization of carbon is 

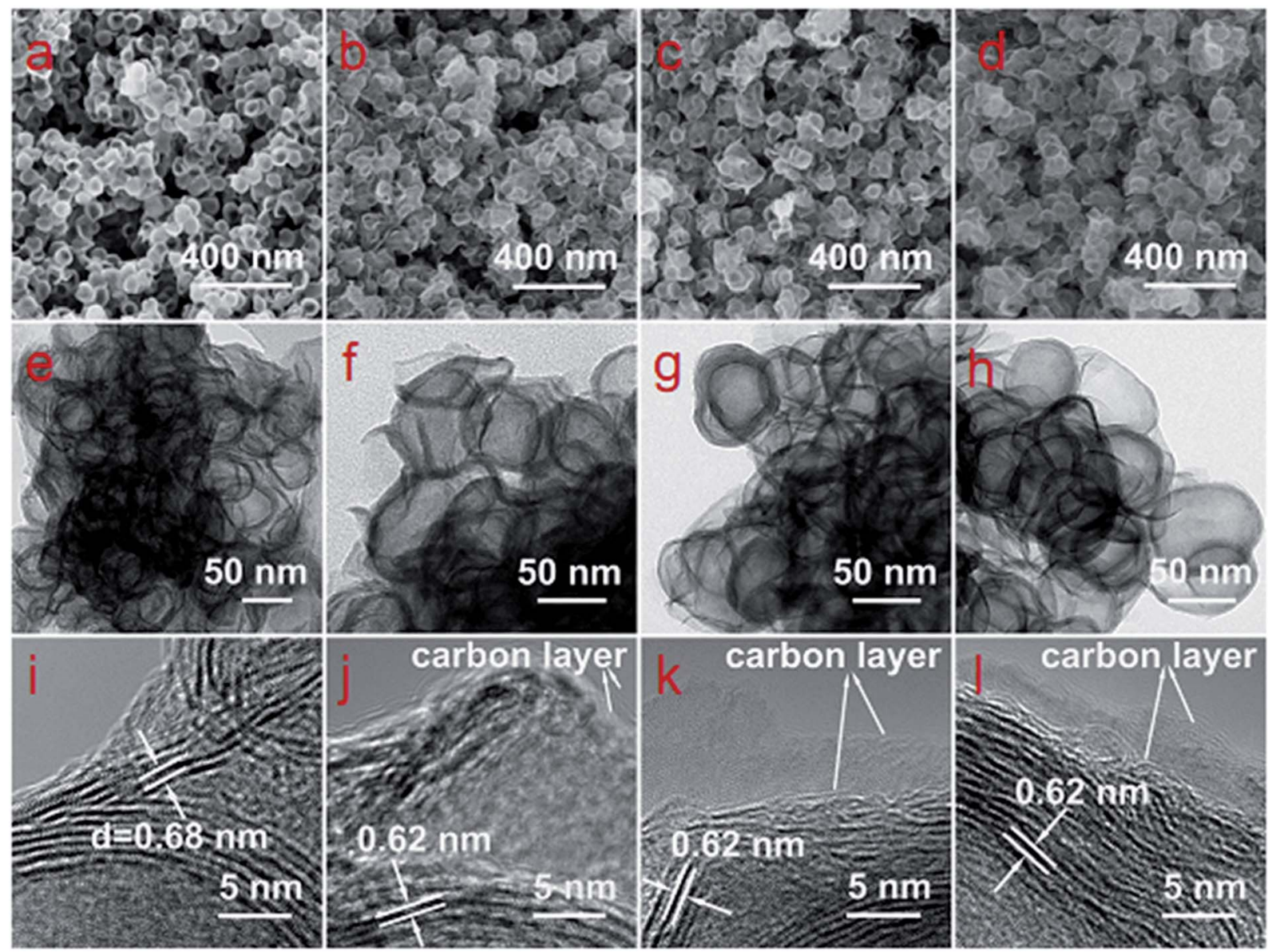

Fig. 2 Morphologies of the $M_{2} S_{2}$ aC nanobowls. (a-d) SEM images, (e-h) TEM images, and (i-l) HRTEM images of MoS 2 (a, e and i), MoS ${ }_{2}\left(\mathrm{CC}_{-}\right.$ 400 (b, f and j), $\mathrm{MoS}_{2} \mathrm{aC}-500$ (c, g and k) and $\mathrm{MoS}_{2} \mathrm{aC}-600$ (d, h and l).

beneficial to improve electrical conductivity of $\mathrm{MoS}_{2} @ \mathrm{C} .{ }^{22}$ FT-IR spectroscopy was employed to explore the chemical functional groups of $\mathrm{MoS}_{2} @ \mathrm{C}$ composites (especially, uniform carbon coating film on the surfaces), as shown in Fig. 3c. The peaks of the FT-IR spectra represent various functional groups. As expected, $\mathrm{MoS}_{2} @ \mathrm{C}-600$ displays various functional groups, including, the $\mathrm{O}-\mathrm{H}$ bond at $3403 \mathrm{~cm}^{-1} \mathrm{C}-\mathrm{H}$ bond at $2918 \mathrm{~cm}^{-1}$, $\mathrm{C}=\mathrm{C}$ bond at $1587 \mathrm{~cm}^{-1}$ and $\mathrm{C}-\mathrm{O}$ bond at $1147 \mathrm{~cm}^{-1}$. Compared to $\mathrm{MoS}_{2} @ \mathrm{C}-400$ and $\mathrm{MoS}_{2} @ \mathrm{C}-500$, the more sharp peaks with high intensities for $\mathrm{MoS}_{2} @ \mathrm{C}-600$ further reveal that oleic acid are highly carbonized on the surfaces of $\mathrm{MoS}_{2}$ at higher annealing temperatures. ${ }^{23}$ In order to determine the carbon content in the $\mathrm{MoS}_{2} @ \mathrm{C}$, thermogravimetric analysis (TGA) was adopted. As shown in Fig. 3d and $\mathrm{S} 3, \uparrow$ the carbon content of $\mathrm{MoS}_{2} @ \mathrm{C}-400, \mathrm{MoS}_{2} @ \mathrm{C}-500$, and $\mathrm{MoS}_{2} @ \mathrm{C}-600$ was estimated to be $15.67,13.44$, and $15.11 \mathrm{wt} \%$, respectively. Apart from the confirmation by HRTEM (Fig. 2j), an additional exothermic peak in the differential thermogravimetric (DTG) curve for $\mathrm{MoS}_{2} @ \mathrm{C}-400$ (Fig. S3bi) also further confirms the lower crystallization of carbon coating for $\mathrm{MoS}_{2} @ \mathrm{C}-400$.

To investigate the chemical states of Mo, S, and $\mathrm{C}$ of the $\mathrm{MoS}_{2}$ and $\mathrm{MoS}_{2} @ \mathrm{C}$, high resolution X-ray photoelectron spectroscopy (XPS) measurements were carried out. As shown in
Fig. 3e, the individual doublet peaks with binding energies at 162 and $163.2 \mathrm{eV}$ in the $\mathrm{S} 2 \mathrm{p}$ spectrum are exactly assigned to the $\mathrm{S}^{2-}$ ions of $\mathrm{MoS}_{2}$, whereas two main peaks with binding ener-

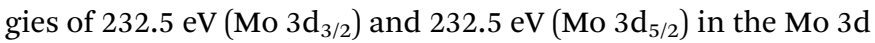
(Fig. 3f) spectrum are well indexed to $\mathrm{Mo}^{4+}$ of $\mathrm{MoS}_{2} \cdot{ }^{12} \mathrm{As}$ expected, the Mo and S XPS peaks Fig. S4, $\uparrow$ and likewise, the $\mathrm{MoS}_{2} @ \mathrm{C}-500$ (Fig. S4d and e†) and $\mathrm{MoS}_{2} @ \mathrm{C}-600$ (Fig. S4g and $\mathrm{h} \dagger)$ peaks are well matched with those of $\mathrm{MoS}_{2}$. In addition, the presence of carbon in the $\mathrm{MoS}_{2}$ @C composites is also further confirmed by distinct XPS C1 speaks at around $285 \mathrm{eV}$ in each C1s spectrum (Fig. S4c, f, and $i \dagger$ ).

Brunauer-Emmett-Teller (BET) analysis was employed to further investigate the pore size distribution and specific surface area of $\mathrm{MoS}_{2}$ and $\mathrm{MoS}_{2} @ \mathrm{C}$. As shown in Fig. 4, a typical hysteresis loop indicating a mesoporous structure is observed in both the $\mathrm{MoS}_{2}$ sample and the $\mathrm{MoS}_{2} @ \mathrm{C}$ samples. $\mathrm{MoS}_{2}$, $\mathrm{MoS}_{2} @ \mathrm{C}-400, \mathrm{MoS}_{2} @ \mathrm{C}-500$, and $\mathrm{MoS}_{2} @ \mathrm{C}-600$ exhibit specific surface areas of $88.21,44.86,49.65$, and $72.75 \mathrm{~m}^{2} \mathrm{~g}^{-1}$, respectively. Owing to the higher degree of carbonization at higher annealing temperature, more mesopore structures can be obtained from the carbon layer, so the $\mathrm{MoS}_{2} @ \mathrm{C}$ composites at higher annealing temperature feature higher BET specific surface areas and total pore volumes, as well as a wider pore size 
a
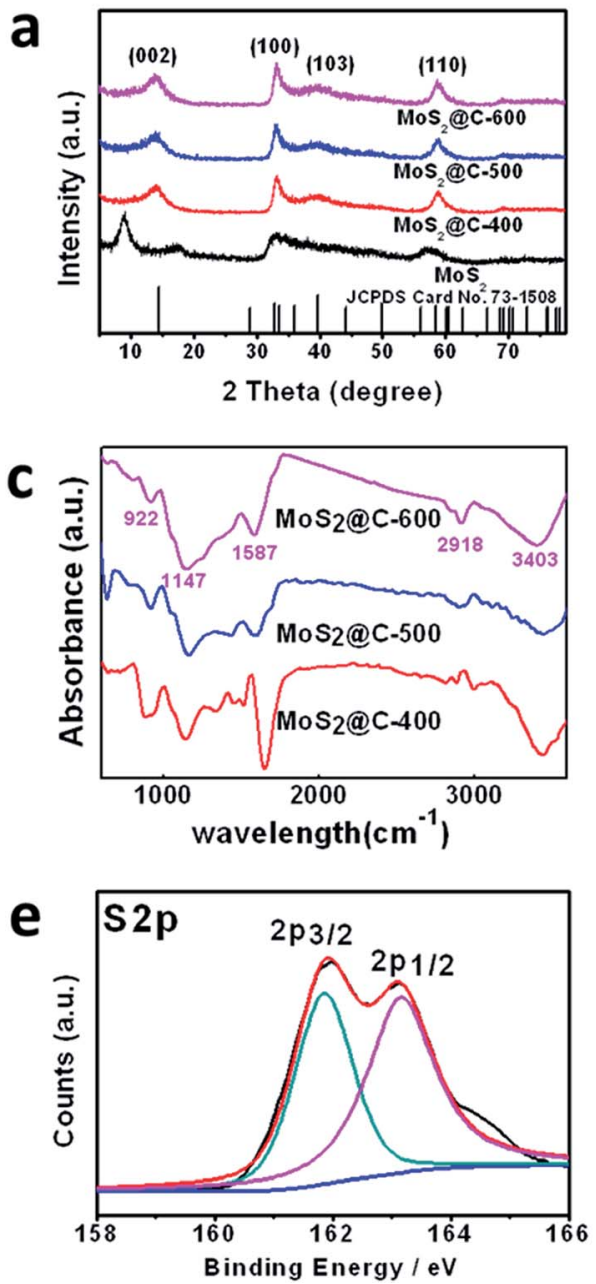
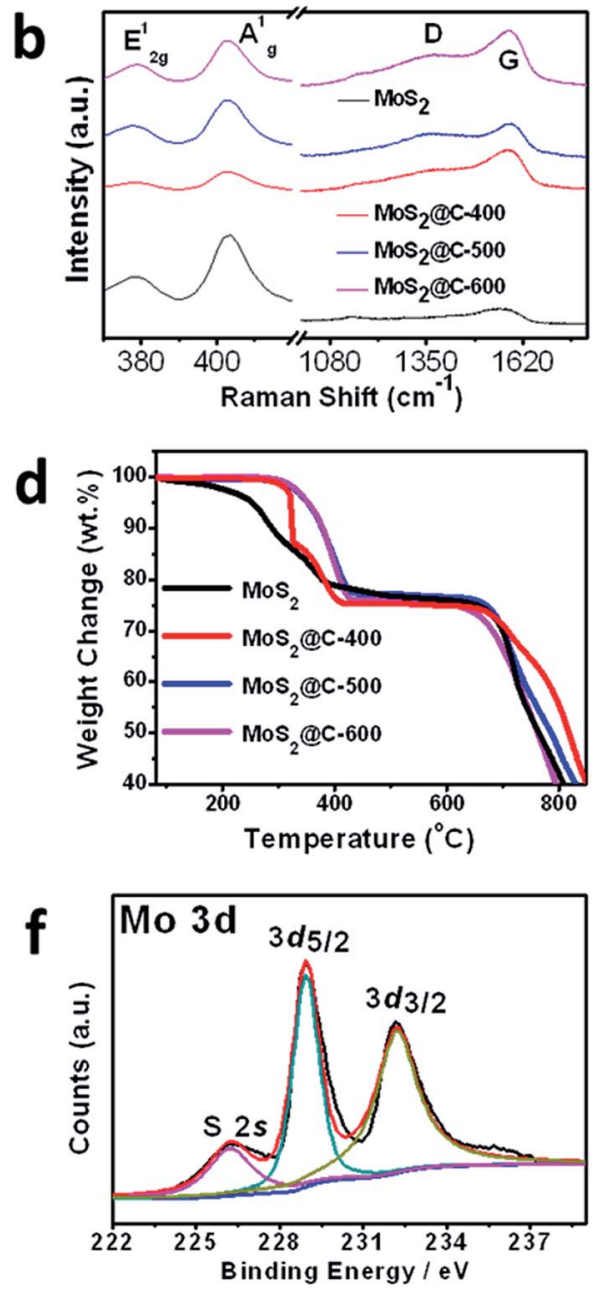

Fig. 3 (a) XRD patterns, (b) Raman spectra, and (d) TGA curves of $\mathrm{MoS}_{2}, \mathrm{MoS}_{2}\left(\mathrm{aC}-400, \mathrm{MoS}_{2} \mathrm{aC}-500\right.$, and MoS 2 aC-600; (c) FI-TR spectra of $\mathrm{MoS}_{2} \mathrm{aC}-400, \mathrm{MoS}_{2} \mathrm{aC}-500$, and $\mathrm{MoS}_{2} \mathrm{aC}-600$; high resolution XPS peaks of (e) Mo 3d, and (f) S 2p of MoS 2 .

distribution (insets of Fig. 4b-d). Besides, due to the carbon coating for inner-sides of $\mathrm{MoS}_{2}$, the void volume of $\mathrm{MoS}_{2}$ is partially occupied, leading to lower surface areas for the $\mathrm{MoS}_{2} @ \mathrm{C}$ than $\mathrm{MoS}_{2}$. Nevertheless, the carbon film coated on the surfaces of $\mathrm{MoS}_{2} @ \mathrm{C}$ nanobowls can provide more favorable paths for electrons fast transportation, protect the electrode pulverization and enhance the mechanical properties of composites during the lithiation-delithiation process.

Fig. S5a-d† presents typical CV curves of the $\mathrm{MoS}_{2}, \mathrm{MoS}_{2} @ \mathrm{C}-$ 400, $\mathrm{MoS}_{2} @ \mathrm{C}-500$, and $\mathrm{MoS}_{2} @ \mathrm{C}-600$ cells at $0.2 \mathrm{mV} \mathrm{s}^{-1}$ in the voltage range of 0.02-3.0 V, respectively. As shown in Fig. S5a, $\uparrow$ $\mathrm{MoS}_{2}$ displays two reduction peaks at 1.1 and $0.3 \mathrm{~V}$ in the first cathodic process. The peak at $1.1 \mathrm{~V}$ can be attributed to insertion of $\mathrm{Li}$ ions into the interlayers of $\mathrm{MoS}_{2}$ (formation of $\mathrm{Li}_{x^{-}}$ $\mathrm{MoS}_{2}$ ), which change from trigonal prisms to octahedra in the $\mathrm{MoS}_{2}$ structure. The weak reduction peak at $1.1 \mathrm{~V}$ indicates the poor ionic conductivity for $\mathrm{MoS}_{2}$. The peak at $0.3 \mathrm{~V}$ is indicative of the conversion of $\mathrm{Li}_{x} \mathrm{MoS}_{2}$ into metallic Mo and $\mathrm{Li}_{2} \mathrm{~S} .{ }^{10}$ In the following anodic process, an oxidation peak is observed at $\sim 1.85 \mathrm{~V}$ (A1) that is attributed to the oxidation of Mo to $\mathrm{MoS}_{2}$, followed by another oxidation peak at $\sim 2.39 \mathrm{~V}$ (A2) associated with the oxidation of $\mathrm{Li}_{2} \mathrm{~S}$. In the following cathodic process, the peaks at 1.1 and $0.3 \mathrm{~V}$ disappear, and two new peaks at about 1.9 (C1) and $1.3 \mathrm{~V}$ (C2) emerge, which can be ascribed to the conversion of $\mathrm{S}$ to $\mathrm{Li}_{2} \mathrm{~S}$ and the association of $\mathrm{Li}^{+}$ions with $\mathrm{Mo}$, respectively. ${ }^{16}$ After the first anodic-cathodic cycle, highly overlapping and distinct pairs of redox peaks (A1-C2 and A2C1) appeared in the subsequent CV curves of $\mathrm{MoS}_{2}$, indicating the good reversibility of $\mathrm{MoS}_{2}$. For the $\mathrm{MoS}_{2} @ \mathrm{C}$ composites, take $\mathrm{MoS}_{2} @ \mathrm{C}-600$ (Fig. 5a or S5d $\dagger$ ) as example, it displays three distinct reduction peaks at approximately 0.95, 0.45, and $0.05 \mathrm{~V}$. Compared to $\mathrm{MoS}_{2}$, the clear peak at $0.95 \mathrm{~V}$ is associated with insertion of $\mathrm{Li}^{+}$ions, while the peak at $0.45 \mathrm{~V}$ is indicative of the conversion process, and the formation of solid electrolyte interphase (SEI), another clear peak at $0.05 \mathrm{~V}$ is related to the lithium ion storage of the amorphous carbon layers. Due to the contribution of the carbon layers, extra $\mathrm{Li}^{+}$ions can be inserted in for $\mathrm{MoS}_{2} @ \mathrm{C}$ composites, so the $\mathrm{MoS}_{2} \mathrm{CV}$ curves (Fig. S5a $\dagger$ ) show weaker reduction peaks at $1.1 \mathrm{~V}$ than $\mathrm{MoS}_{2} @ \mathrm{C}$ (Fig. S5b$\mathrm{d} \dagger$ ). Similarly, highly overlapped CV curves in the subsequent cycles further support the high reversibility of $\mathrm{MoS}_{2} @ \mathrm{C}$. It should be noted that the oxidation peaks at $\sim 1.85 \mathrm{~V}$ in all three 

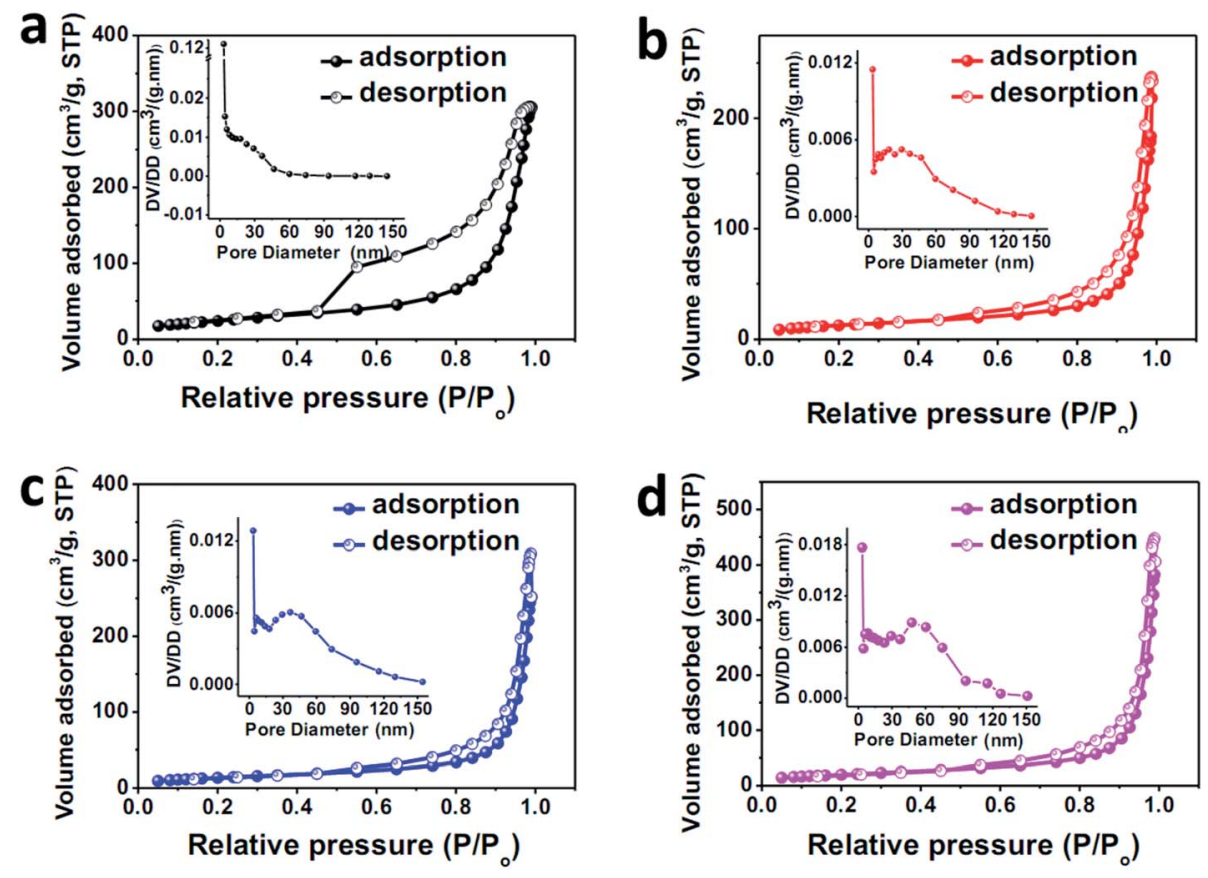

Fig. 4 BET nitrogen adsorption and desorption isotherms of (a) $\mathrm{MoS}_{2}$, (b) MoS 2 aC-400, (c) MoS 2 aC-500, and (d) MoS 2 aC-600. Inset of each plot: pore size distribution of the corresponding sample.

anodic processes and the reduction peak at $1.1 \mathrm{~V}$ in the second and third cathodic processes are extremely weak for all $\mathrm{MoS}_{2} @ \mathrm{C}$ composites compared with that of $\mathrm{MoS}_{2}$. This is probably due to the strong interaction between lithium ions and carbon nanosheets, overlapping the oxidation peaks of Mo.

Fig. 5b presents the first discharge-charge profiles for the $\mathrm{MoS}_{2}, \mathrm{MoS}_{2} @ \mathrm{C}-400, \mathrm{MoS}_{2} @ \mathrm{C}-500$, and $\mathrm{MoS}_{2} @ \mathrm{C}-600$ at $0.1 \mathrm{C}$ in the voltage range of $0.02-3 \mathrm{~V}$. As can be seen, the dischargecharge electrochemical behavior of $\mathrm{MoS}_{2}$ and $\mathrm{MoS}_{2} @ \mathrm{C}$ were almost consistent with the cyclic voltammetry (CV) measurements. Along with the discharge-charge profiles of $\mathrm{MoS}_{2}$ and $\mathrm{MoS}_{2} @ \mathrm{C}$ at $0.1 \mathrm{C}$, the discharge-charge profiles of $\mathrm{MoS}_{2} @ \mathrm{C}-600$ at various C-rates from 0.2 to $10 \mathrm{C}$ are also presented in Fig. $5 \mathrm{c}$. The electrochemical behaviors of $\mathrm{MoS}_{2}$ and $\mathrm{MoS}_{2} @ \mathrm{C}$ agree well with previous reports. ${ }^{\mathbf{1 5 , 2 4}}$

To compare the rate capability of $\mathrm{MoS}_{2}$ and $\mathrm{MoS}_{2} @ \mathrm{C}$, we charged and discharged the cells for 60 cycles in the voltage range of $0.02-3 \mathrm{~V}$ at current densities from $0.2 \mathrm{C}$ to $10 \mathrm{C}$ (Fig. $5 \mathrm{~d}$ ). As shown in Fig. 5d, the initial discharge capacities of the $\mathrm{MoS}_{2}$, $\mathrm{MoS}_{2} @ \mathrm{C}-400, \mathrm{MoS}_{2} @ \mathrm{C}-500$, and $\mathrm{MoS}_{2} @ \mathrm{C}-600$ are 1461.5, 1405.3, 1478.1 and $1558.3 \mathrm{~mA} \mathrm{~h} \mathrm{~g}^{-1}$ at $0.1 \mathrm{C}$ (assume $1 \mathrm{C}=500$ $\mathrm{mA} \mathrm{g}^{-1}$ ), with initial coulombic efficiencies of $67.8 \%, 71.6 \%$, $74.6 \%$, and $75.6 \%$, respectively. When the $\mathrm{C}$ rate is increased from 0.2 to $10 \mathrm{C}$ and changes back to $0.1 \mathrm{C}$, the $\mathrm{MoS}_{2} @ \mathrm{C}-600$ exhibits the higher average charge capacities of $958.6(0.2 \mathrm{C})$, 792.5 (0.5C), 657.6 (1C), 504 (2C), 363.3 (5C), and 171.5 (10C) mA $\mathrm{h} \mathrm{g}^{-1}$, followed by the $\mathrm{MoS}_{2} @ \mathrm{C}-500$, than MoS2@C-400 and $\mathrm{MoS}_{2}$. When the charge/discharge current density changes from $10 \mathrm{C}$ back to $0.1 \mathrm{C}$, the specific capacity of all these four samples can be well restored, indicating extraordinarily high cycling stabilities. The detailed numerical results are listed in Table 1.
To further compare their rate capabilities, the capacity retention vs. C-rates of $\mathrm{MoS}_{2}$ and $\mathrm{MoS}_{2} @ \mathrm{C}$ composites is presented in Fig. S6a, $\uparrow$ obviously $\mathrm{MoS}_{2} @ \mathrm{C}-500$ and $\mathrm{MoS}_{2} @ \mathrm{C}-600$ present higher capacity retention (as a function of C-rate) than $\mathrm{MoS}_{2}$ or $\mathrm{MoS}_{2} @ \mathrm{C}-400$. The improved rate capability is attributed to the carbon coating film, resulting the improved conductivity and enhanced mechanical properties of $\mathrm{MoS}_{2} @ \mathrm{C}-500$ or $\mathrm{MoS}_{2} @ \mathrm{C}$ 600 during the discharge-charge process. Although a thin carbon film was also coated on the surface of $\mathrm{MoS}_{2} @ \mathrm{C}-400$, $\mathrm{MoS}_{2} @ \mathrm{C}-400$ presented poorer rate capability than $\mathrm{MoS}_{2} @ \mathrm{C}$ 500 or $\mathrm{MoS}_{2} @ \mathrm{C}-600$ because of its lower degree of carbonization at $400{ }^{\circ} \mathrm{C}$.

Fig. 5e presents the relatively long-term cycling performances of the $\mathrm{MoS}_{2}$ and $\mathrm{MoS}_{2} @ \mathrm{C}$ at $0.2 \mathrm{C}$. As can be seen, the $\mathrm{MoS}_{2}, \mathrm{MoS}_{2} @ \mathrm{C}-400, \mathrm{MoS}_{2} @ \mathrm{C}-500$, and $\mathrm{MoS}_{2} @ \mathrm{C}-600$ exhibited initial discharge capacities of 928.8, 898.3, 1076.4, and 1164.4 $\mathrm{mA} \mathrm{h} \mathrm{g}^{-1}$, with an initial coulombic efficiency of $69.9 \%, 73.5 \%$, $76.9 \%$, and 79.1\%, respectively. After 150 cycles, the $\mathrm{MoS}_{2}$, $\mathrm{MoS}_{2} @ \mathrm{C}-400, \mathrm{MoS}_{2} @ \mathrm{C}-500$, and MoS 2 @-600 cells can maintain discharge capacities of 621.6, 605.1, 846.0, and 839.3 $\mathrm{mA} \mathrm{h} \mathrm{g}^{-1}$ with initial capacity retention of $66.9 \%, 67.4 \%, 78.6 \%$, and $72.1 \%$, respectively. Despite the different capacities and capacity retention, $\mathrm{MoS}_{2}$ and $\mathrm{MoS}_{2}$ @C all present average coulombic efficiencies of $\sim 99 \%$, further indicating their highly stable structures during the lithiation-delithiation processes. Furthermore, the long-term cycling performances of $\mathrm{MoS}_{2}$, $\mathrm{MoS}_{2} @ \mathrm{C}-400, \mathrm{MoS}_{2} @ \mathrm{C}-500$, and $\mathrm{MoS}_{2} @ \mathrm{C}-600$ at the higher Crate of $1 \mathrm{C}$ are also compared in Fig. 5e and $\mathrm{S} 7 . \dagger$ As can be seen, $\mathrm{MoS}_{2} @ \mathrm{C}-600$ delivered a higher discharge capacity of $858.2 \mathrm{~mA} \mathrm{~h} \mathrm{~g}^{-1}$ compared with the other three samples (Fig. S7†). After 150 cycles, $\mathrm{MoS}_{2} @ \mathrm{C}-500$ maintained higher 

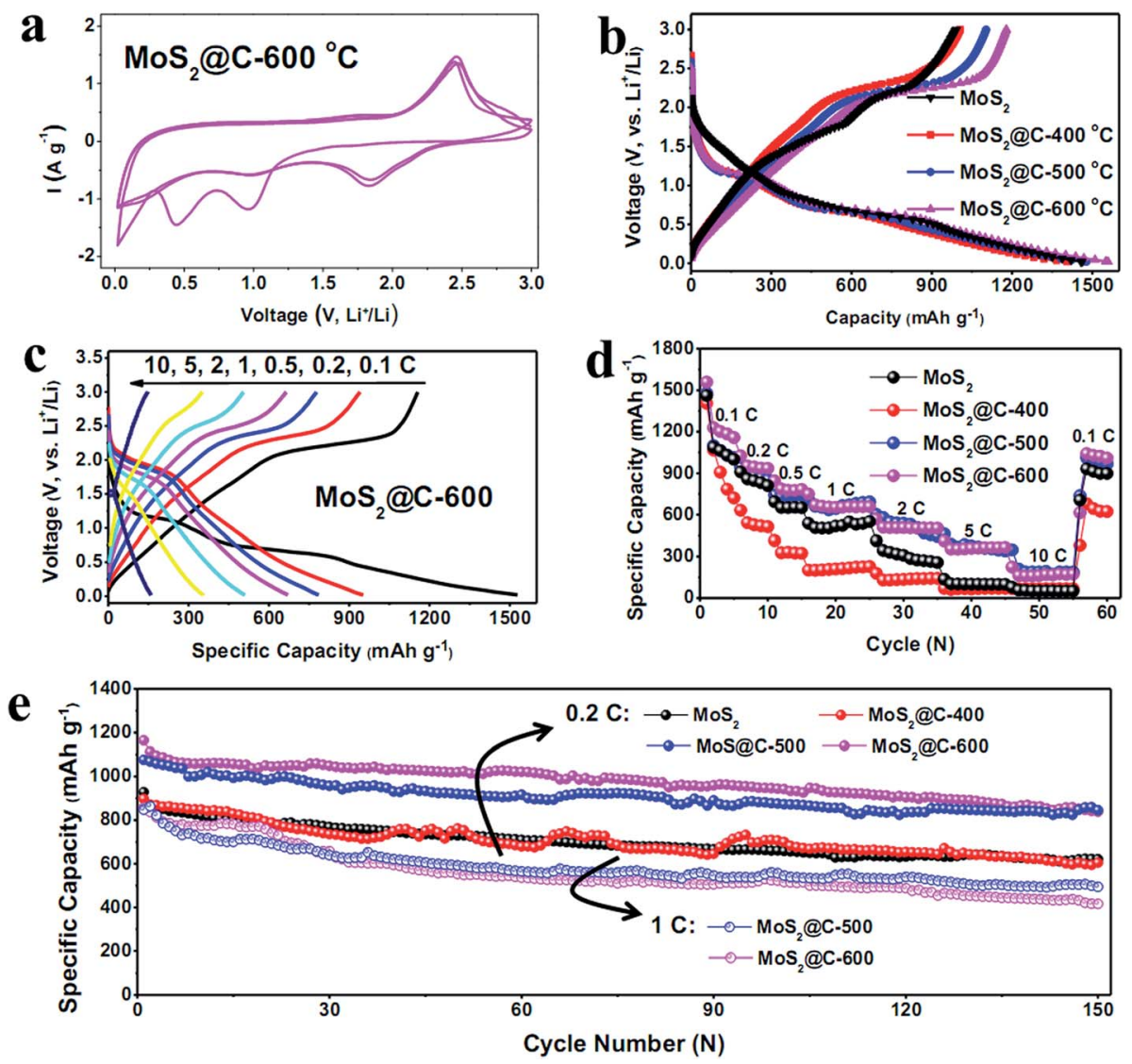

Fig. 5 (a) CV curves of $\mathrm{MoS}_{2} \mathrm{aC}-600$ for the first 3 cycles at $0.2 \mathrm{mV} \mathrm{s}^{-1}$; (b) discharge-charge profiles at $0.1 \mathrm{C}$ (assume $1 \mathrm{C}=0.5 \mathrm{~A} \mathrm{~g}^{-1}$ ) of $\mathrm{MoS}_{2}$, $\mathrm{MoS}_{2} \mathrm{aC}-400, \mathrm{MoS}_{2} \mathrm{aC}-500$, and $\mathrm{MoS}_{2} \mathrm{aC}-600$; (c) discharge-charge profiles of $\mathrm{MoS}_{2} \mathrm{aC}-600$ at various C-rates from 0.1-10C; (d) rate capability measurements of $\mathrm{MoS}_{2}, \mathrm{MoS}_{2} \mathrm{aC}-400, \mathrm{MoS}_{2} @ \mathrm{aC}-500$, and $\mathrm{MoS}_{2} @ \mathrm{CC}-600$; and (e) long-term cycling performance for 150 cycles of $\mathrm{MoS}_{2}, \mathrm{MoS}_{2} @ \mathrm{CC}-400, \mathrm{MoS}_{2} \mathrm{aC}-500$, and MoS $2 \mathrm{aC}-600$.

Table 1 The detailed rate capability numerical results of $\mathrm{MOS}_{2}$, $\mathrm{MoS}_{2} \mathrm{aC}-400, \mathrm{MoS}_{2} \mathrm{aC}-500$, and $\mathrm{MoS}_{2} \mathrm{aC}-600$ when the $\mathrm{C}$ rate is increased from 0.2 to $10 \mathrm{C}$ and changes back to $0.1 \mathrm{C}$

\begin{tabular}{lccccrrr}
\hline & $0.2 \mathrm{C}$ & $0.5 \mathrm{C}$ & $1 \mathrm{C}$ & \multicolumn{1}{c}{$2 \mathrm{C}$} & \multicolumn{1}{c}{$5 \mathrm{C}$} & $10 \mathrm{C}$ & \multicolumn{1}{c}{$0.1 \mathrm{C}$} \\
\hline $\mathrm{MoS}_{2}$ & 850.9 & 659.9 & 537.5 & 270.1 & 99.6 & 51.0 & 910.5 \\
$\mathrm{MoS}_{2} @ \mathrm{C}-400$ & 546.7 & 344.2 & 221.1 & 140.9 & 69.4 & 67.3 & 642.6 \\
$\mathrm{MoS}_{2} @ \mathrm{C}-500$ & 892.5 & 737.1 & 679.1 & 482.6 & 353.9 & 185.3 & 988.4 \\
$\mathrm{MoS}_{2} @ \mathrm{C}-600$ & 958.6 & 792.5 & 657.6 & 504.0 & 363.3 & 171.5 & 1024.9
\end{tabular}

initial capacity retention of $58.5 \%$ compared with $\mathrm{MoS}_{2} @ \mathrm{C}-600$ (48.3\%) over the 150 cycles, although $\mathrm{MoS}_{2}$ @C-600 delivered a higher capacity than $\mathrm{MoS}_{2} @ \mathrm{C}-500$ in the initial cycles. The higher initial capacity retention at $1 \mathrm{C}$ indicates the excellent anode performance of $\mathrm{MoS}_{2}$ @C-500 at higher C-rate. This is mainly associated with the moderate degree of crystallization of the carbon film of $\mathrm{MoS}_{2} @ \mathrm{C}-500$, which could provide good mechanical properties during the repeated discharge-charge cycles at higher C-rates, leading to the enhanced cycling stability.

To investigate the kinetics of $\mathrm{MoS}_{2}$ and $\mathrm{MoS}_{2} @ \mathrm{C}$ nanobowls, electrochemical impedance spectra (EIS) were conducted on the cells before cycling, after rate capability measurements, and after long-term cycling measurements at $0.2 \mathrm{C}$, over the frequency range from $1 \mathrm{MHz}$ to $0.05 \mathrm{~Hz}$. As shown in Fig. 6a-c, all the spectra include a depressed semicircle in the high- and medium-frequency regions, which could be assigned to the resistance associated with lithium-ion diffusion through the solid electrolyte interphase (SEI) film $\left(R_{\mathrm{S}}\right)$ and the charge transfer resistance $\left(R_{\mathrm{ct}}\right)$, respectively, and a clear $\sim 45^{\circ}$ inclined line in the low-frequency region, which could be considered to be Warburg impedance $(W){ }^{25}$ The $R_{\mathrm{ct}}$ is a key indicator for the kinetics of the electrode material. The $R_{\mathrm{ct}}$ was calculated by using the equivalent circuit model shown in the inset of Fig. 6a. The fabricated model also includes electrolyte resistance $\left(R_{\mathrm{e}}\right)$, a constant phase element (CPE-1), and a non-ideal constant phase element (CPE-2). Compared with the fresh cells before cycling (Fig. 6a), all the corresponding cells after rate measurements (Fig. 6b) or long-term cycling measurements (Fig. 6c) at $0.2 \mathrm{C}$ apparently show decreased $R_{\mathrm{ct}}$ of the electrode materials. This is mainly due to the electrode-electrolyte activation after deep discharge-charge cycles. As estimated from the fabricated model (inset of Fig. 6a), the relatively low $R_{\mathrm{ct}}$ (less than $100 \Omega$ ) of the electrodes after rate capability measurements and long-term cycling measurements further indicate the excellent structural and chemical stability of the electrode 

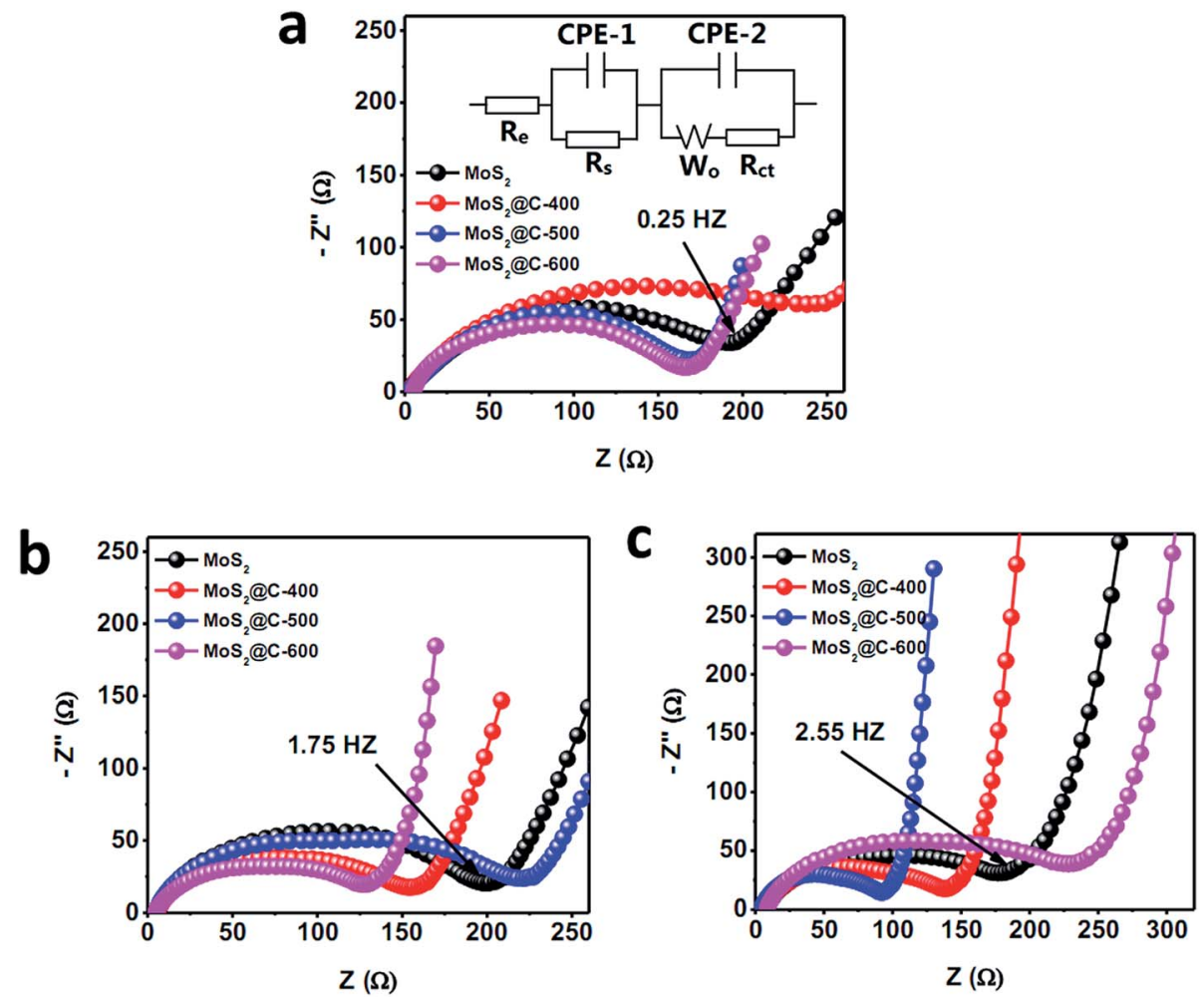

Fig. 6 Electrochemical impedance spectra (EIS) of $\mathrm{MoS}_{2}, \mathrm{MoS}_{2} \mathrm{aC}-400, \mathrm{MoS}_{2} \mathrm{aC}-500$, and MoS 2 (aC-600: (a) before cycling, (b) after rate capability measurements (shown in Fig. $3 \mathrm{~d}$ ) and (c) after long-term cycling measurements (shown in Fig. 3e) at 0.2C. Inset of (a): equivalent circuit model.

materials, facilitating ions fast transportation. The $R_{\mathrm{ct}}$ values of $\mathrm{MoS}_{2}$ and $\mathrm{MoS}_{2} @ \mathrm{C}$ before and after cycling increase in the order of $\mathrm{MoS}_{2} @ \mathrm{C}-600<\mathrm{MoS}_{2} @ \mathrm{C}-500<\mathrm{MoS}_{2} @ \mathrm{C}-400<\mathrm{MoS}_{2}$ (before rate measurements) and $\mathrm{MoS}_{2} @ \mathrm{C}-500<\mathrm{MoS}_{2} @ \mathrm{C}-600<$ $\mathrm{MoS}_{2} @ \mathrm{C}-400<\mathrm{MoS}_{2}$ (after rate measurements), indicating highest kinetics of $\mathrm{MoS}_{2} @ \mathrm{C}-600$ or $\mathrm{MoS}_{2} @ \mathrm{C}-600$ among the series electrodes. These results are almost consistent with their electrochemical performance.

\section{Conclusion}

In summary, we have successfully fabricated the $\mathrm{MoS}_{2}$ and $\mathrm{MoS}_{2} @ \mathrm{C}$ composites with high uniformity and a well-defined nanobowl structure through a facial solvothermal method, followed by an annealing process. Compared to $\mathrm{MoS}_{2}$, the $\mathrm{MoS}_{2} @ \mathrm{C}$ presented the excellent electrochemical performance for LIBs. The $\mathrm{MoS}_{2} @ \mathrm{C}-500$ maintained a high reversible capacity of $846 \mathrm{~mA} \mathrm{~h} \mathrm{~g}^{-1}$ at $0.2 \mathrm{C}$ over 150 cycles, corresponding to an initial capacity retention of $78.4 \%$. The excellent electrochemical performance of $\mathrm{MoS}_{2} @ \mathrm{C}-500$ nanobowls is attributed to their unique nanobowl structure. The nanobowl structure provides large accessible surface areas and pore volumes for easy electrolyte penetration and rapid $\mathrm{Li}^{+}$diffusion, as well as the accommodation of volume variation during the repeated charge-discharge cycles, thus leading to enhanced capacity and rate capability. The $\mathrm{MoS}_{2} @ \mathrm{C}$ nanobowls are expected to be an ideal anode material for high-energy LIBs in future.

\section{Acknowledgements}

This work was supported by the National Natural Science Foundation of China (Grant No. 51302079). We also thank Dr Tania Silver from Institute for Superconducting and Electronic Materials (University of Wollongong) for revising our manuscript.

\section{References}

1 (a) V. Etacheri, R. Marom, R. Elazari, G. Salitra and D. Aurbach, Energy Environ. Sci., 2011, 4, 3243; (b) M. M. Thackeray, C. Wolverton and E. D. Isaacs, Energy Environ. Sci., 2012, 5, 7854.

2 (a) A. Manthiram, J. Phys. Chem. Lett., 2011, 2, 176; (b) J. W. Fergus, J. Power Sources, 2010, 195, 939; (c) J. Xu, S. Dou, H. Liu and L. Dai, Nano Energy, 2013, 2, 439.

3 K. S. Novoselov, V. I. Falko, L. Colombo, P. R. Gellert, M. G. Schwab and K. Kim, Nature, 2012, 490, 192.

4 (a) N. A. Kaskhedikar and J. Maier, Adv. Mater., 2009, 21, 2664; (b) E. Yoo, J. Kim, E. Hosono, H.-S. Zhou, T. Kudo and I. Honma, Nano Lett., 2008, 8, 2277; (c) Z.-S. Wu, W. Ren, L. Xu, F. Li and H.-M. Cheng, ACS Nano, 2011, 5, 5463; (d) Z.-L. Wang, D. Xu, H.-G. Wang, Z. Wu and X.-B. Zhang, ACS Nano, 2013, 7, 2422; (e) J. Xu, I. Y. Jeon, J. M. Seo, S. Dou, L. Dai and J. B. Baek, Adv. Mater., 2014, 26, 7317 . 
5 (a) R. Dominko, D. Arčon, A. Mrzel, A. Zorko, P. Cevc, P. Venturini, M. Gaberscek, M. Remskar and D. Mihailovic, Adv. Mater., 2002, 14, 1531; (b) C. Feng, J. Ma, H. Li, R. Zeng, Z. Guo and H. Liu, Mater. Res. Bull., 2009, 44, 1811; (c) J. Xiao, D. Choi, L. Cosimbescu, P. Koech, J. Liu and J. P. Lemmon, Chem. Mater., 2010, 22, 4522.

6 (a) A. C. Neto, Phys. Rev. Lett., 2001, 86, 4382; (b) Y. Liu, H. Nan, X. Wu, W. Pan, W. Wang, J. Bai, W. Zhao, L. Sun, X. Wang and Z. Ni, ACS Nano, 2013, 7, 4202.

7 (a) Y. Liu, X. Zhu, Z. Duan and X. Xie, Chem. Commun., 2013, 49, 10305; (b) X. Zhu, K. Wang, D. Yan, S.-R. Le, R.-J. Ma, K.-N. Sun and Y.-T. Liu, Chem. Commun., 2015, 51, 11888; (c) L. Pan, X.-D. Zhu, X.-M. Xie and Y.-T. Liu, J. Mater. Chem. A, 2015, 3, 2726; (d) Z.-Q. Duan, Y.-C. Sun, Y.-T. Liu, X.-M. Xie and X.-D. Zhu, RSC Adv., 2014, 4, 41543; (e) L. Pan, Y.-T. Liu, X.-M. Xie and X.-D. Zhu, Chem.-Asian J., 2014, 9, 1519.

8 S. Ding, D. Zhang, J. S. Chen and X. W. D. Lou, Nanoscale, 2012, 4, 95.

9 (a) X. Fang, X. Yu, S. Liao, Y. Shi, Y.-S. Hu, Z. Wang, G. D. Stucky and L. Chen, Microporous Mesoporous Mater., 2012, 151, 418; (b) G. Huang, T. Chen, W. Chen, Z. Wang, K. Chang, L. Ma, F. Huang, D. Chen and J. Y. Lee, Small, 2013, 9, 3693; (c) Y. Shi, Y. Wang, J. I. Wong, A. Y. S. Tan, C.-L. Hsu, L.-J. Li, Y.-C. Lu and H. Y. Yang, Sci. Rep., 2013, 3, 2169; (d) P. Wang, H. Sun, Y. Ji, W. Li and X. Wang, Adv. Mater., 2014, 26, 964.

10 L. Yang, S. Wang, J. Mao, J. Deng, Q. Gao, Y. Tang and O. G. Schmidt, Adv. Mater., 2013, 25, 1180.

11 J. Wang, J. Liu, D. Chao, J. Yan, J. Lin and Z. X. Shen, Adv. Mater., 2014, 26, 7162.

12 Z. Wan, J. Shao, J. Yun, H. Zheng, T. Gao, M. Shen, Q. Qu and H. Zheng, Small, 2014, 10, 4975.

13 C. Zhao, J. Kong, X. Yao, X. Tang, Y. Dong, S. L. Phua and X. Lu, ACS Appl. Mater. Interfaces, 2014, 6, 6392.
14 (a) J. Xiao, X. Wang, X. Q. Yang, S. Xun, G. Liu, P. K. Koech, J. Liu and J. P. Lemmon, Adv. Funct. Mater., 2011, 21, 2840; (b) K. Chang and W. Chen, Chem. Commun., 2011, 47, 4252; (c) K. Chang and W. Chen, J. Mater. Chem., 2011, 21, 17175; (d) S. Ding, J. S. Chen and X. W. D. Lou, Chem.-Eur. J., 2011, 17, 13142; (e) D. Kong, H. He, Q. Song, B. Wang, W. Lv, Q.-H. Yang and L. Zhi, Energy Environ. Sci., 2014, 7, 3320; (f) C. Wang, W. Wan, Y. Huang, J. Chen, H. H. Zhou and X. X. Zhang, Nanoscale, 2014, 6, 5351; (g) F. Zhou, S. Xin, H. W. Liang, L. T. Song and S. H. Yu, Angew. Chem., Int. Ed., 2014, 53, 11552.

15 K. Chang, D. Geng, X. Li, J. Yang, Y. Tang, M. Cai, R. Li and X. Sun, Adv. Energy Mater., 2013, 3, 839.

16 Z. Wang, T. Chen, W. Chen, K. Chang, L. Ma, G. Huang, D. Chen and J. Y. Lee, J. Mater. Chem. A, 2013, 1, 2202.

17 J. Xie, J. Zhang, S. Li, F. Grote, X. Zhang, H. Zhang, R. Wang, Y. Lei, B. Pan and Y. Xie, J. Am. Chem. Soc., 2013, 135, 17881.

18 H. Yu, C. Ma, B. Ge, Y. Chen, Z. Xu, C. Zhu, C. Li, Q. Ouyang, P. Gao and J. Li, Chem.-Eur. J., 2013, 19, 5818.

19 (a) H. Liu, D. Su, R. Zhou, B. Sun, G. Wang and S. Z. Qiao, Adv. Energy Mater., 2012, 2, 970; (b) Z. Hu, L. Wang, K. Zhang, J. Wang, F. Cheng, Z. Tao and J. Chen, Angew. Chem., Int. Ed., 2014, 126, 13008.

20 J. Zhang, Y. Wang, Z. Lin and F. Huang, Cryst. Growth Des., 2010, 10, 4285.

21 S. K. Das, R. Mallavajula, N. Jayaprakash and L. A. Archer, J. Mater. Chem., 2012, 22, 12988.

22 A. C. Ferrari and D. M. Basko, Nat. Nano, 2013, 8, 235.

23 J. Zhang, H. Yang, G. Shen, P. Cheng, J. Zhang and S. Guo, Chem. Commun., 2010, 46, 1112.

24 (a) X. Xiong, W. Luo, X. Hu, C. Chen, L. Qie, D. Hou and Y. Huang, Sci. Rep., 2015, 5, 9254; (b) J. Zhou, J. Qin, X. Zhang, C. Shi, E. Liu, N. Zhao and C. He, ACS Nano, 2015, 9, 3837.

25 J. Xu, S.-L. Chou, Q.-F. Gu, H.-K. Liu and S.-X. Dou, J. Power Sources, 2013, 225, 172. 